- This is the first assessment of the oral health needs of single homeless adults in North and West Belfast.

- The study population had greater experience of dental caries and periodontal disease compared with adults in Northern Ireland (NI) who took part in the 1998 Adult Dental Health Survey.

- The widespread use of smoking and use and abuse of alcohol marked the study population as a high-risk group for oral cancer, with the increased risk calculated as 95 times greater than the NI population as a whole.

- Homeless people are not a homogeneous population, therefore social exclusion and psycho-social functioning should be considered when planning appropriate oral healthcare services for this diverse client group.

\title{
Homeless in North and West Belfast: an oral health needs assessment
}

\author{
J. Collins ${ }^{1}$ and R. Freeman ${ }^{2}$
}

\begin{abstract}
Aim The aim was to assess the oral health needs of a homeless population residing in North and West Belfast Health and Social Services Trust area, in order to determine levels of unmet need and allow recommendations for service delivery to be made.
\end{abstract}

Method A sample of single homeless people was gathered using a snowballing sampling technique. Fourteen hostels located in North and West Belfast were visited in tandem with the homeless healthcare co-ordinator. All consenting participants were asked to complete a detailed medical history questionnaire and a questionnaire to assess their health and psycho-social needs, dental anxiety and oral healthrelated quality of life. All participants received an oral examination. Results Three hundred and seventeen homeless people consented to take part. Two hundred and sixty-seven (84\%) were male. Thirtythree percent of participants had mental health problems including psychotic illness, depression and anxiety. Forty-three percent of the sample stated they were addicted to alcohol and $3 \%$ were registered injecting drug users. Five percent (16) of the sample had soft tissue swellings of which two were found to be oral cancer. The participants had a mean $D_{3 c \mathrm{v}} \mathrm{MFT}$ of $16.16(95 \% \mathrm{Cl}: 15.71,17.46)$. Seventy-five percent of the sample had bleeding gums and calculus; however only $4 \%$ had pocket depths of $6 \mathrm{~mm}$ or more. Dental anxiety status was related to dental disease experience which impacted negatively on quality of life. Forty-seven percent of the participants felt at least occasionally self-conscious and/or felt ashamed by the appearance of their teeth. Conclusions Health and psychosocial factors associated with being homeless must be incorporated into the delivery of context-sensitive oral healthcare for this socially excluded population.

'Community Dental Service, Ballyowen Health Centre, 179 Andersontown Road, Belfast, BT11 9EA; ${ }^{2 *}$ Dental Health Services Research Unit, University of Dundee ${ }^{*}$ Correspondence to: Professor Ruth Freeman, Dental Health Services Research Unit, Mackenzie Building, Kirsty Semple Way, Dundee, DD2 4BF

Email: r.e.freeman@chs.dundee.ac.uk

Online article number E31

Refereed Paper - accepted 14 December 2006

DOI: $10.1038 /$ bdj.2007.473

${ }^{\circ}$ British Dental Journal 2007; 202: E31

\section{INTRODUCTION}

Homelessness is a growing concern in the United Kingdom as a whole, but in particular in Northern Ireland, where the number of households presenting as homeless has greatly increased in recent years from an average of 10,000 in 1995 to 17,000 in 2003/2004. ${ }^{1}$

Homelessness is difficult to define, with agencies applying differing definitions. ${ }^{2}$ These variations affect the numbers recorded as homeless in official surveys. In addition, there are a number of people who are homeless, but are living with friends or staying in temporary accommodation. This group are referred to as the hidden homeless. They are by definition excluded when statistics are being gathered, affecting the accuracy of estimates of this population. ${ }^{2}$

The homeless population is comprised of a varied, dynamic group of people who defy stereotyping. The image of the homeless person as a shabbily dressed older man is very wide of the mark. Although two-thirds of the homeless are male, ${ }^{3}$ many are young and have been made homeless for a variety of reasons. Among the most common reasons for homelessness in Northern Ireland (NI) are relationship breakdown and alcohol, ${ }^{3}$ and more specific to this locality is homelessness as a result of violence and paramilitary intimidation. ${ }^{1}$

To be homeless is to be lonely. Research into experiences of the homeless has shown that homeless people feel very isolated, vulnerable to attack and exploitation..$^{4-6}$ Although living in a hostel full of other people, homeless people can feel very alone and experience low self-esteem. They have little or no social contact with others and few have relatives or friends to rely on in times of need. These factors, in conjunction with poverty, illness and geographical isolation, contribute to the degree of social exclusion experienced by homeless people. ${ }^{7}$

The level of social exclusion combined with the transient and nomadic lifestyle of the homeless person affects the uptake of healthcare services by this group, presenting many barriers, such as lack of trust and unrealistic expectations of the health professional, to provision of healthcare, including dental services. ${ }^{8}$ 


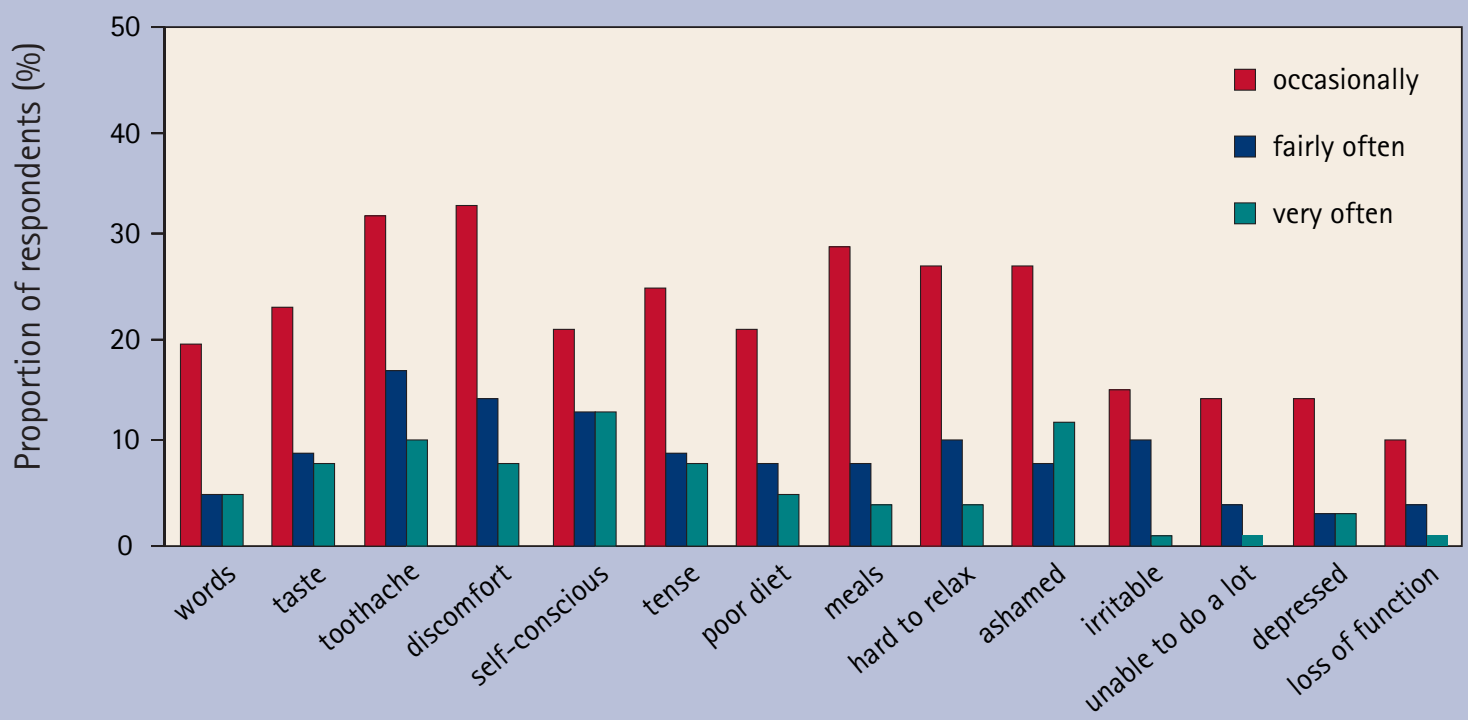

Oral health impacts

Fig. 1 Frequency of reported problems

These barriers must be overcome in order to provide satisfactory dental care appropriate to the needs of this vulnerable group.

In 2004 the British Dental Association (BDA) published Dental Care for Homeless People, which called for improvements in the delivery of dental care to homeless people. ${ }^{8}$ This survey was conducted in response to this report. ${ }^{8}$ Hence the aim was to assess the oral health needs of homeless people residing in North and West Belfast in order to allow recommendations for service delivery for this socially excluded group to be made.

\section{METHOD}

\section{The sample}

A sample was obtained from a variety of hostels for single homeless people and rough sleepers' drop-in centres within the North and West Belfast area over a period of 18 months.

Working in liaison with the North and West Health and Social Services Trust's homeless healthcare co-ordinator, who had established contacts with each hostel, a sample of single homeless people was obtained using a snowballing sampling technique. ${ }^{9}$ The people resident in hostels constantly changes, with homeless people moving between hostels and areas. This meant that included in the survey was anyone willing to participate when the dental team were visiting the hostel being included. As each hostel was visited many times, a snowball effect was generated, increasing the number of people participating in the oral health survey.

Each individual approached was provided with written and verbal information explaining the aim of the survey and requesting their participation. They were informed that participation was voluntary and a decision not to take part would not affect their present or future dental treatment. Written consent was obtained. Ethical approval was obtained from the Trust ethics committee.

\section{The questionnaire}

The questionnaire consisted of three parts. Section 1 consisted of a series of yes/no answers, which inquired of the participants' medical history details. This included questions on demography, reasons for homelessness and previous occupational status, as well as use of tobacco, alcohol and drugs.

In section 2, dental anxiety status was assessed using the modified dental anxiety scale (MDAS) which is a five-item inventory. ${ }^{10,11}$ The questions assess dental anxiety with regard to waiting for dental treatment, drilling, scale and polish and local anaesthesia. The participants rated their dental anxiety on a five-point scale which ranges from not anxious (1) to extremely anxious (5). The scores range from 5 to 25 , with scores over 19 indicating dental phobia. The normative value for a general practice patient population is 10.7 (SD 4.6).

The third section assessed oral health-related quality of life using the shortened Oral Health Impact Profile (OHIP-14) format. ${ }^{12,13}$ This index, based on Locker's ${ }^{12}$ adapted World Health Organisation classification of disease impacts, was designed to measure how self-reported experience of dental disease impacted upon life in terms of function and well-being. The shortened version of the OHIP (OHIP-14) ${ }^{12,13}$ was chosen as being most suitable for this purpose. Participants were asked to rate their experience of impacts of oral health problems (such as discomfort) on a five point Likert scale ranging from never (0) to very often (4).

\section{Administration of the questionnaire}

The questionnaire was piloted on an equivalent group from another Trust. The participants were asked to complete the questionnaire prior to the oral examination. Many of those surveyed required help with completing the questionnaire due to poor eyesight and/or poor literacy skills.

\section{Oral health examination}

Oral health examinations were conducted using WHO guidelines. ${ }^{14}$ The oral health examination included an examination of the soft tissues, obvious decay experience and periodontal health. The dental status recorded as obvious decay experience $\left(D_{3 c v} M F T\right)^{15}$ recognised cavitation and visual dentine caries $\left(D_{3 \mathrm{cv}}\right)$ on the basis of a clinical examination conducted 
without the use of probes. Periodontal health was assessed using the Community Periodontal Index (CPI). A single, independent, calibrated community dentist (JC) examined all participants. JC was chaperoned by the healthcare co-ordinator for the homeless population in North and West Belfast and her dental nurse.

The oral health examinations were conducted following collection of medical history details. The equipment used was a Daray light (or where facilities did not stretch to an electrical supply, a pen torch), a mirror and a WHO periodontal probe. Other items such as cotton wool pellets, rolls and tweezers were used where it was necessary to remove debris in order to visualise the oral structures. The full examination was conducted under standardised conditions observing normal infection control protocols. ${ }^{16}$

Intra-examiner reliability was measured by re-examining a 10\% random sample of all participants. The Kappa statistic was used to give an accurate measure of intra-examiner reproducibility. The intra-examiner reliability was high, with $99 \%$ agreement.

\section{Procedure}

The oral health examination was carried out in a room in the hostel, which had been set aside for other purposes and afforded some privacy to those being examined. For some who were banned from entering certain hostels, but who had agreed to participate, the dental examination was carried out on the street.

\section{Statistical analysis}

The data were coded and entered onto a computer using SPSS version 12 . The data were subjected to frequency distributions and t-tests.

\section{RESULTS}

\section{Sample}

In total 317 people were included in this survey. All those approached agreed to participate. Although all the participants completed the questionnaire, some elected not to answer questions asking about their marital status (32\%), children (24\%) or why they had become homeless (24\%). In addition, 80 participants were unable to complete the MDAS and 75 did not complete OHIP-14. This was due to their mental health state or degree of inebriation at the time of the survey. All participants in the survey had an oral examination. Thirty-five individuals did not have a periodontal examination as their medical history precluded probing.

\section{Demographic profile}

Two hundred and sixty-seven (84\%) of the sample were male. The ages of those examined ranged from 16 years to 91 years. The mean age was 39.6 (95\% CI: 37.9, 41.3) years.

Of those who answered the question on marital status (216), 151 participants described themselves as single. The remainder stated that they were married (13), separated (31), divorced (16) or widowed (3). Similarly, of those 240 participants who responded to the question on children, 43\% (102) stated that they had children. None of the sample had contact with their children.

All of the participants were unemployed. The majority of

\begin{tabular}{|c|c|c|c|c|}
\hline \multirow{2}{*}{$\begin{array}{l}\text { Dental } \\
\text { health status }\end{array}$} & \multirow{2}{*}{$\begin{array}{l}\text { Age group } \\
\text { (n) }\end{array}$} & \multirow{2}{*}{ Mean } & \multicolumn{2}{|c|}{$95 \%$ confidence intervals } \\
\hline & & & Lower interval & Upper interval \\
\hline \multirow{6}{*}{$\begin{array}{l}\text { Decay into } \\
\text { dentine }\left(D_{3 \mathrm{cv}}\right)\end{array}$} & $\begin{array}{l}16-24 \\
(56)\end{array}$ & 2.9 & 1.9 & 3.9 \\
\hline & $\begin{array}{l}25-34 \\
(73)\end{array}$ & 4.5 & 3.3 & 5.7 \\
\hline & $\begin{array}{l}35-44 \\
(74)\end{array}$ & 3.1 & 2.4 & 3.8 \\
\hline & $\begin{array}{l}45-54 \\
(57)\end{array}$ & 3.8 & 2.4 & 5.2 \\
\hline & $\begin{array}{l}55-64 \\
(32)\end{array}$ & 3.5 & 2.0 & 5.0 \\
\hline & $\begin{array}{l}65+ \\
(25)\end{array}$ & 2.3 & 0.6 & 3.9 \\
\hline \multirow{6}{*}{ Missing teeth } & $\begin{array}{l}16-24 \\
(56)\end{array}$ & 1.2 & 0.7 & 1.7 \\
\hline & $\begin{array}{l}25-34 \\
(73)\end{array}$ & 4.3 & 3.2 & 5.4 \\
\hline & $\begin{array}{l}35-44 \\
(74)\end{array}$ & 5.7 & 4.4 & 7.0 \\
\hline & $\begin{array}{l}45-54 \\
(57)\end{array}$ & 10.0 & 7.8 & 12.1 \\
\hline & $\begin{array}{l}55-64 \\
(32)\end{array}$ & 17.7 & 14.5 & 20.9 \\
\hline & $\begin{array}{l}65+ \\
(25)\end{array}$ & 19.0 & 14.6 & 23.5 \\
\hline \multirow{6}{*}{ Filled teeth } & $\begin{array}{l}16-24 \\
(56)\end{array}$ & 4.1 & 3.0 & 5.2 \\
\hline & $\begin{array}{l}25-34 \\
(73)\end{array}$ & 5.3 & 4.4 & 6.2 \\
\hline & $\begin{array}{l}35-44 \\
(74)\end{array}$ & 7.5 & 6.3 & 8.6 \\
\hline & $\begin{array}{l}45-54 \\
(57)\end{array}$ & 6.4 & 5.0 & 7.9 \\
\hline & $\begin{array}{l}55-64 \\
(32)\end{array}$ & 4.0 & 2.0 & 6.1 \\
\hline & $\begin{array}{l}65+ \\
(25)\end{array}$ & 1.3 & 0.2 & 2.4 \\
\hline \multirow{6}{*}{$\begin{array}{l}\text { Obvious decay } \\
\text { experience } \\
\text { ( } D_{3 c \mathrm{c} M F T)}\end{array}$} & $\begin{array}{l}16-24 \\
(56)\end{array}$ & 8.3 & 6.7 & 9.8 \\
\hline & $\begin{array}{l}25-34 \\
(73)\end{array}$ & 14.2 & 12.6 & 15.8 \\
\hline & $\begin{array}{l}35-44 \\
(74)\end{array}$ & 16.4 & 15.2 & 17.6 \\
\hline & $\begin{array}{l}45-54 \\
(57)\end{array}$ & 20.3 & 18.7 & 21.9 \\
\hline & $\begin{array}{l}55-64 \\
(32)\end{array}$ & 25.3 & 23.8 & 26.9 \\
\hline & $\begin{array}{l}65+ \\
(25)\end{array}$ & 22.7 & 19.3 & 26.0 \\
\hline
\end{tabular}

the sample (85\%) stated that they had never been employed or in paid work. Those who had previously worked had been employed in occupations such as labouring (8\%), catering $(3 \%)$ or retail $(1 \%)$. Other job types previously held were reported as: receptionist, dental technician, sailor, engineer and hairdresser. 


\section{Reasons for becoming homeless}

From those participants who had responded to the question on the reason for homelessness, the most common reason given was alcoholism (21\%). Other reasons included relationship breakdown (20\%), domestic violence (16\%), paramilitary intimidation (5\%), recent release from prison (2\%), drug or gambling addictions (2\%), death of a relative (1\%) or the individual's own choice (1\%).

\section{Medical history}

Sixty-nine percent (217) of the participants stated that they had no medical health problems. However, the remainder of the sample had heart disease (5\%), diabetes $(4 \%)$ or blood-borne infections (2\%) such as hepatitis C or HIV. Two hundred and fifty-four (80\%) of the sample smoked tobacco.

Twenty-nine percent (93) of the sample suffered from mental health problems which included psychotic illness (29) and major depression and anxiety (64). Sixty-seven participants took anti-psychotic and/or anti-depressant medication. Seventy-five percent (237) drank alcohol, with 43\% (102) stating that they were alcoholics. Eighteen percent (57) were regular drug users and of these, ten were registered injecting drug users.

\section{Oral health status}

The data on the dental health status of the participants by age group is shown in Table 1.

\section{Extra-oral health and soft tissue status}

For the majority of the sample (97\%) there were no obvious signs of extra-oral or intra-oral pathology. Bruises and cuts were observed in two participants with a further three having visible extra-oral swelling. Three participants had angular cheilitis. Sixteen participants (5\%) had soft tissue lesions, two of which were later diagnosed as squamous cell carcinoma.

\section{Obvious decay experience}

The mean $\mathrm{D}_{3 \mathrm{cv}}$ MFT was 16.6 (95\% CI: 15.7, 17.4). The largest component of the $\mathrm{D}_{3 \mathrm{cv}}$ MFT was the missing teeth (7.6 [95\% CI: $6.7,8.6]$ ), with the number of missing teeth ranging from 1 to 28. The number of decayed teeth ranged from 1 to 24 teeth. The mean number of decayed teeth $\left(\mathrm{D}_{3 \mathrm{cv}}\right)$ was 3.5 (95\% CI: 3.0, 4.0). The number of filled teeth ranged from 0 to 22 teeth. The mean number of filled teeth was 5.4 (95\% CI: 4.8, 5.9).

\section{Periodontal health}

Only 8\% (22) of those who had a periodontal examination (282) had no obvious signs of gingival or periodontal disease. Seventyfive percent of the sample had a CPI score of 2: that is, calculus detected during probing. Four percent of the sample population had a CPI score of 4: that is, they had pocket depths of $6 \mathrm{~mm}$ or more. The mean CPI score was 1.9 (95\% CI: 1.8, 2.0).

\section{Dental anxiety status}

Of the 237 participants who completed the MDAS, the mean scores for dental anxiety were 12.5 (95\% CI: 11.5, 13.5). Twenty-eight percent (65) scored over 19, indicating that they were dentally phobic. Mean score for dental anxiety for the sample population (12.5; SD 7.7) was significantly greater than the normative mean scores (10.7; SD 4.6) $(t=2.92 ; \mathrm{p}<0.05)$.

The sample was split into higher and lower dental anxiety

\begin{tabular}{|c|c|c|c|c|}
\hline $\begin{array}{l}\text { Oral health } \\
\text { status }\end{array}$ & $\begin{array}{l}\text { Low dental anxiety } \\
\text { status }(n=128) \\
\text { mean }(95 \% \mathrm{Cl})\end{array}$ & $\begin{array}{l}\text { High dental anxiety } \\
\text { status }(n=109) \\
\text { mean }(95 \% \mathrm{Cl})\end{array}$ & $\mathrm{t}$ & $p$ \\
\hline $\begin{array}{l}\text { Obvious decay } \\
\text { experience } \\
\left(D_{3 c v} M F T\right)\end{array}$ & $16.9(15.5,18.3)$ & $15.5(14.0,17.0)$ & 1.3 & 0.17 \\
\hline Decayed teeth & $3.3(2.6,4.1)$ & $4.0(3.1,4.8)$ & -1.1 & 0.27 \\
\hline Missing teeth & $7.8(6.3,9.4)$ & $7.0(5.5,8.4)$ & 0.8 & 0.40 \\
\hline Filled teeth & $5.7(4.8,6.5)$ & $4.5(3.7,5.3)$ & 1.9 & $<0.05$ \\
\hline CPI score & $1.9(1.8,2.1)$ & $2.0(1.9,2.2)$ & -0.9 & 0.34 \\
\hline
\end{tabular}

\begin{tabular}{|c|c|c|c|c|}
\hline $\begin{array}{l}\text { Oral health } \\
\text { status }\end{array}$ & $\begin{array}{l}\text { Low oral health } \\
\text { impact experience } \\
(\mathrm{n}=114) \\
\text { mean }(95 \% \mathrm{Cl})\end{array}$ & $\begin{array}{l}\text { High oral health } \\
\text { impact experience } \\
(\mathrm{n}=128) \\
\text { mean }(95 \% \mathrm{Cl})\end{array}$ & $t$ & $p$ \\
\hline $\begin{array}{l}\text { Obvious decay } \\
\text { experience } \\
\left(D_{3 c v} M F T\right)\end{array}$ & $15.0(13.5,16.5)$ & $17.2(15.9,18.5)$ & -2.1 & 0.03 \\
\hline Decayed teeth & $3.0(2.2,3.7)$ & $4.1(3.3,4.9)$ & -2.1 & 0.04 \\
\hline Missing teeth & $6.7(5.1,8.3)$ & $7.9(6.5,9.3)$ & -0.07 & 0.28 \\
\hline Filled teeth & $5.2(4.3,6.1)$ & $5.1(4.3,6.0)$ & 0.1 & 0.85 \\
\hline CPI score & $1.9(1.8,2.1)$ & $2.0(1.9,2.2)$ & -0.9 & 0.34 \\
\hline
\end{tabular}

status using a median split. Those scoring 13 and above (109) were designated as having high dental anxiety status and those scoring 12 or less (128) as having low dental anxiety status. Those respondents with high dental anxiety status compared to those with low dental anxiety status had significantly lower mean numbers of filled teeth. No other significant differences were shown (Table 2). Those participants with mental health problems (14.0 [95\% CI: 12.1, 15.8]) had significantly higher mean scores for dental anxiety than those with no mental health problems (11.8 [95\% CI: 10.7, 13.0]) $(\mathrm{t}=2.0 ; \mathrm{p}<0.05)$.

\section{Oral health-related quality of life}

Of those 242 who completed OHIP-14, the mean score for oral health-related quality of life was 14.8 (95\% Cl: 13.0, 16.8). Forty-two participants experienced ten impacts at least 'occasionally' and 38 participants experienced 14 impacts 'very often'. The types of oral health impacts experienced are shown in Figure 1. The most commonly report impacts experienced were problems with discomfort, toothache and difficulty in eating meals. Forty-seven percent of the participants stated 
that they felt at least 'occasionally' self-conscious or ashamed regarding the appearance of their teeth. Thirteen percent of the sample 'very often' felt self-conscious and 12\% 'very often' felt ashamed concerning the appearance of their teeth.

Interestingly, those participants who had previously been in paid employment had lower mean scores for oral health impacts (14.1; 95\% CI: 12.31, 15.9) compared with those who had never been in employment $(17.7 ; 95 \% \mathrm{CI}: 13.8,21.7)(\mathrm{t}=1.74 ; \mathrm{p}=0.08)$. The sample was split into high and low oral health-related quality of life impact groups using a median split. Those scoring 15 and above (128) were designated as experiencing high impacts and those scoring 14 or less (114) as experiencing low impacts. Those participants in the high impact group had significantly greater mean $\mathrm{D}_{3 \mathrm{cv}} \mathrm{MFT}$ scores and significantly greater mean numbers of decayed teeth compared with those participants in the lower oral health impact group (Table 3).

\section{DISCUSSION}

The 2004 BDA report Dental Care For Homeless People ${ }^{8}$ stated that more needed to be done to provide homeless people with accessible dental services and called for local needs assessments to be carried out in order to determine levels of need and allow recommendations for the planning of delivery of dental care. This survey, in response to that report, sought to address these issues.

In terms of their age, substance abuse and experience of physical and mental ill health, this group of homeless people from North and West Belfast seemed to reflect the profile of homeless populations described elsewhere. ${ }^{1,3,17-23}$ A few of the Belfast participants in addition had experienced paramilitary intimidation and violence which lead to their homeless status. ${ }^{1,3}$ Paramilitary intimidation still had some effect upon their current life circumstances, with one participant stating that (s)he was unable to attend for hospital appointments for fear of being 'murdered'. The chaotic lifestyle and fears of being refused entry to hostels appeared to be relevant to the reported use of drugs. Only small numbers of participants admitted to drug use and there was a sense that the use of illegal drugs was under-reported due to concerns of being expelled and refused subsequent entry to a favoured hostel. ${ }^{18}$

The report Dental Care for Homeless People advised that more should be done to alert homeless people to dental health issues, which as it states, "cannot be divorced from the broader context of general health'. ${ }^{8}$ In view of this, factors which were known to impact adversely upon health or place an individual at a higher risk of disease were explored in this survey. The widespread use of smoking and use and abuse of alcohol marked this homeless population as a high-risk group for oral cancer. In the population surveyed, 16 participants were observed to have soft tissue lesions. Of these lesions, the majority were non-suspicious ulcers, which had healed on review. Three participants were referred for urgent specialist investigation; two of the lesions were found to be squamous cell carcinoma. In essence this meant that being homeless increased the risk of contracting oral cancer by 95 times compared with the NI population as a whole. ${ }^{24}$

As might be expected, this group of homeless people had greater experience of dental caries compared with adults in NI who took part in the 1998 Adult Dental Health Survey. ${ }^{25}$ They had greater numbers of missing teeth, decayed teeth and lower numbers of filled teeth. Their level of periodontal health was also poorer. These findings were indicative of the high levels of unmet restorative need and the absence of oral hygiene regimes in homeless populations. The effect of being older and homeless for longer was reflected in the increased experience of missing teeth and periodontal disease. While these findings were to be expected, they seemed to highlight the effect of prolonged homelessness upon oral health status..$^{21-23}$

It was of interest that this homeless population was significantly more dentally anxious than the general population. When higher and lower dental anxiety groups were compared, it seemed that dental fear was reflected in an avoidance of dental treatment, suggesting that some of the participants were dentally phobic. In fact, $27 \%$ of the sample had MDAS scores that were indicative of dental phobia. It is possible that their dental phobia was a consequence of falsely connecting past and possibly frightening life events with fearful treatment experiences, but it is equally likely that their dental fears were exacerbated by their mental health status. This latter supposition is supported in the findings, since those participants with a history of mental illness had significantly higher mean scores for dental anxiety compared with the others. Therefore it would seem that the increased prevalence of dental phobia $(27 \%)$ in this group of homeless people compared with the general population (10\%) was related to their higher experience of psychotic illness, major depression and anxiety. This finding gives support to the view that dental phobia, as distinct from dental anxiety, is not a disease entity in is own right but is a symptom of mental illness. ${ }^{26}$

Sizeable proportions of the participants stated that they experienced oral health impacts. Increased experience of discomfort, toothache and difficulty with eating due to decayed teeth were expected findings, however nearly 50\% of the sample stated that they felt at least 'occasionally' ashamed and/or felt self-conscious about the appearance of their teeth. ${ }^{22}$ This would suggest that for these homeless people, quality of life was affected by their oral health status and in particular the appearance of their teeth. Nevertheless, it could be argued that the state of homelessness in itself is a greater factor in whether someone is tense or unable to relax rather than simple oral health problems. The work of Palma and Nordenram ${ }^{27}$ is of importance in this debate. They suggest that homeless people 'describe and interpret [their oral health] in terms of loss and recovery' and as such, oral health mirrors the loss of a permanent home, friends and family. It may be postulated that the experience of oral health-related impacts is, by force, a reflection of the impacts of being homeless.

It was observed that some individuals were more marginalised than others. Some of the participants had relatives and friends with whom they visited and socialised; others had groups of friends with whom they wandered about from place to place; for others, there were no such social links. This last sub-section of homeless people were truly isolated, excluded from family and society either by social circumstances or by their own choice. These observations provided additional evidence that far from being a homogenous group, the homeless are a disparate population of individuals, difficult to stereotype or neatly categorise. ${ }^{2,28}$ The members of this homeless population experienced a range of levels of social exclusion, with some more marginalised than others due to the variety of 
degrees with which they interfaced with society. ${ }^{23}$ The degree of their social exclusion was reflected in their experience of disease, including oral disease. Therefore, experience of social exclusion and psycho-social functioning are factors which must be considered when planning appropriate and acceptable oral healthcare services for this diverse client group.

There are limitations to this survey. It may be suggested that this was a self-selected sample; for instance, this survey did not access the hidden homeless ${ }^{3}$ and thus may not be representative of the homeless in North and West Belfast. Nevertheless, this potential limitation was recognised by the researchers and the assistance of the homeless healthcare coordinator was invaluable. Her knowledge of and acquaintance with this homeless population and her ability to help them overcome their fears enabled those who were more excluded and isolated to participate in the survey. Some respondents did not care to answer some of the social history questions, whilst the altered mental state of others (either due to mental illness or suspected inebriation) prevented all but basic details from being recorded. It is proposed that the above limitations must be considered as realistic difficulties which occur when accessing this group of socially excluded people in order to develop sensitive and appropriate oral healthcare for them.

In conclusion, the homeless population is a special needs group characterised by an increased prevalence of ill-health, chaotic lifestyles, deprivation and social exclusion. ${ }^{1-4,28}$ The findings of this study would suggest that the homeless are not a homogenous group and experience varying degrees of social exclusion as reflected in their physical and mental ill-health. In order to deliver oral health services, it is recommended that psychosocial factors in addition to physical (health and oral health) factors must be considered. Dental fears and anxieties about the appearance of their teeth are real concerns for this client group and must be incorporated into planning initiatives. In addition, their chaotic lifestyle means that a combination of treatment opportunities (such as mobile clinics with other health professionals in hostel localities) must be provided in conjunction with consultation and essential assistance from healthcare co-ordinators for homeless populations.

Particular thanks are due to Susan Semple, healthcare co-ordinator for the homeless population in North and West Belfast, who facilitated the data gathering and whose expertise in interacting with the homeless population was invaluable.
We would like to acknowledge the funding provided by the North and West Belfast Local Health Trust and Social Care Group.

1. Northern Ireland Housing Executive. Facts and figures. www.nihe.gov.uk/homelessnet/hless_facts. Accessed October 2005.

2. Northern Ireland Executive. Promoting social inclusion. www.newtsnni.gov. uk/psi/promotingsocialinclusion.htm. Accessed October 2005.

3. Regional Housing Authority for Northern Ireland. The Northern Ireland housing market review and perspectives 2004-2007. Belfast: Housing Executive, 2004.

4. Craig T, Timms P. Facing up to social exclusion: services for homeless mentally ill people. Int Rev Psychiatry 2000; 12: 206-211.

5. Ballintyne S. Unsafe streets. New Economy 1999; 6: 94-98.

6. Semple S. How single homeless perceived their own health. Unpublished MSc thesis. University of Ulster at Jordanstown, Northern Ireland, 2003.

7. Phelan J. The stigma of homelessness: the impact of the label 'homeless' on attitudes towards poor persons. Soc Psychol Q 1997; 60: 323-338.

8. British Dental Association. Dental care for homeless people. Policy statement. London: British Dental Association, 2004.

9. Knight P T. Small scale research. London: Sage Publications, 2002.

10. Humphris G M, Morrison T, Lindsay S J. The Modified Dental Anxiety Scale: validation and United Kingdom norms. Community Dent Health 1995; 12: 143-150.

11. Humphris G M, Freeman R, Campbell J, Tuutti H, D'Souza V. Further evidence for the reliability and validity of the Modified Dental Anxiety Scale. Int Dent J 2000; 50: 367-370

12. Slade D E. Derivation and validation of a short-form oral health impact profile. Community Dent Oral Epidemiol 1997; 25: 284-290.

13. Locker D. Measuring oral health: a conceptual framework. Community Dent Health 1998; 5: 5-13.

14. World Health Organisation. Oral health survey - basic methods. 4th ed. Geneva: WHO, 1997.

15. Pitts N B, Evans D J, Pine C M. British Association for the Study of Community Dentistry (BASCD) diagnostic criteria for caries prevalence surveys - 1996/97. Community Dent Health 1997; 14: 6-9.

16. North and West Belfast Health and Social Services Trust. Cross infection policy: guidelines for dental staff. Belfast: North and West Belfast HSST, 2002.

17. Crane M, Warnes A M, Fu R. Developing homelessness prevention practice: combining research evidence and professional knowledge. Health Soc Care Community 2006; 14: 156-166.

18. Fischer P J, Breakley W R. The epidemiology of alcohol, drug, and mental disorders among homeless persons. Am Psychol 1991; 46: 1115-1128.

19. Montauk S L. The homeless in America: adapting you practice. Am Fam Physician 2006; 74: 1132-1138.

20. Phelan J C, Link B G. Who are 'the homeless'? Reconsidering the stability and composition of the homeless population. Am J Public Health 1999; 89: 1334-1338.

21. Gelberg L, Linn S L, Rosenberg D J. Dental health of homeless adults. Spec Care Dentist 1988; 8: 167-172.

22. De Palma P, Frithiof L, Persson L, Klinge B, Halldin J, Beijer U. Oral health of homeless adults in Stockholm, Sweden. Acta Odontol Scand 2005; 63: 50-55.

23. Luo Y, McGrath C. Oral health status of homeless people in Hong Kong. Spec Care Dentist 2006; 24: 150-154.

24. Cancer Research UK. UK oral cancer incidence statistics. http://info. concernresearchuk.org/cancerstats/types/oral/incidence/. Accessed July 2006.

25. Kelly M, Steele J, Nuttall N et al. Adult dental health survey. Oral health in the United Kingdom 1998. London: TSO, 2000. http://www.statistics.gov.uk/ssd/ surveys/adult_dental_health_survey.asp. Accessed July 2006.

26. Freeman R. A psychodynamic theory for dental phobia. Br Dent J 1998; 184: 170-172.

27. De Palma P, Nordenram G. The perceptions of homeless people in Stockholm concerning oral health and consequences of dental treatment: a qualitative study. Spec Care Dentist 2005; 25: 289-295.

28. Amster R. Patterns of exclusion: sanitizing space, criminalising homelessness. Social Justice 2003; 30: 195-202. 